Калашникова О.В., Мурзыванова С.В., Плаксина Т.И.

17. Красная книга Самарской области. Т. 1. Редкие виды растений, лишайников и грибов. Тольятти: ИЭВБ РАН, 2007. 372 с.

18. Красная книга Самарской области. Т. 1. Редкие виды растений и грибов / под ред. С.А. Сенатора и С.В. Саксонова. Самара: Издательство Самарской государственной областной академии (Наяновой), 2017. 284 c.

\section{ECOLOGICAL AND FLORISTIC FEATURES OF THE SAMARA REGION NATURE MONUMENT «KOPEYKA MOUNTAIN»}

(C) 2018
19. Плаксина Т.И. Редкие и исчезающие растения Самарской области. Самара: Самарский университет, 1998. $272 \mathrm{c.}$

20. Раков Н.С., Саксонов С.В., Сенатор С.А. Редкие и уязвимые сосудистые растения Самарской области // Известия Самарского научного центра Российской академии наук. 2012. Т. 14, № 1-7. С. 1838 1843.

\title{
(1)
}

\begin{abstract}
Kalashnikova Olga Vladimirovna, candidate of biological sciences, training master of Ecology, Botany and Nature Protection Department Murzyvanova Svetlana Vadimovna, student of Biology Department

Plaksina Tamara Ivanovna, doctor of biological sciences, professor of Ecology, Botany and Nature Protection Department Samara National Research University (Samara, Russian Federation)
\end{abstract}

Abstract. The paper presents the results of a comprehensive analysis of the nature monument «Kopeyka Mountain» flora nine years after the last descriptions of this area. To identify the ecology-floristic features of the mountain, a complete ecology-floristic characteristic was given according to the classical pattern. The taxonomic analysis has showed that on the stony steppe there are 150 species of higher plants, including 106 genera and 39 families. The leading families in the number of species are Asteraceae (28 species), Fabaceae (21) and Poaceae (11). A large number of species of the Fabaceae is one of the distinguishing features of Kopeyka Mountain. The predominant biomorph under the classification of I.G. Serebryakov is a group of herbaceous perennials, namely rod-root (39 species) and short-stemmed plants ( 25 species). The predominance of these life forms illustrates a high adaptability of plants to the conditions of their growth. The predominant hygromorph of xerophytic plants (67 species), revealed during the ecological analysis by N.M. Matveyev, also shows high suitability of the local flora to a lack of moisture in the mountainous terrain. Ecology-geographical analysis showed that the mountain-steppe group of plants was the largest in the number of species. A chorological analysis was also conducted, which showed the presence of all seven types of areals, of which Eurasian type (73 species) and European (34) were the leading ones. Endemic (45 species) and relic (15) taxa have been noted, which raises this monument of nature to a considerable height. In the flora of Kopeyka Mountain, 8 species are represented in the Red Data Book of the Russian Federation and 43 species are in the Red Data Book of the Samara Region. A decrease in the number of species in the flora of Kopeyka Mountain is a concern. It is necessary to introduce monitoring to protect the nature monument «Kopeyka Mountain».

Keywords: natural monument «Kopeyka Mountain»; Pokhvistnevsky District; Samara Region; taxonometric analysis; biomorphological analysis; ecology-geographical analysis; chorological analysis; Russian Federation Red Data Book; Red Data Book of Samara Region.

УДК 574.2

Статья поступила в редакцию 11.03.2018

\section{О ВОЗМОЖНОЙ РОЛИ РЕЦЕПТОРОВ ДОФАМИНА DОР-1 И DOP-3 В РЕГУЛЯЦИИ ТЕПЛОУСТОЙЧИВОСТИ ПОВЕДЕНИЯ CAENORHABDITIS ELEGANS MAUPAS} (C) 2018 Калинникова Татьяна Борисовна, кандидат биологических наук,
заведующий лабораторией экспериментальной экологии

Колсанова Руфина Рифкатовна, кандидат биологических наук, научный сотрудник лаборатории экспериментальной экологии

Белова Евгения Борисовна, младший научный сотрудник лаборатории экспериментальной экологии Институт проблем экологии и недропользования Академии наук Республики Татарстан

$$
\text { (2. Казань, Российская Федерачия) }
$$

Хакимова Диляра Махмутриевна, кандидат медицинских наук, старший преподаватель кафедры морфологии и общей патологии Казанский (Приволжский) федеральный университет (2. Казань, Российская Федерация)

Гайнутдинов Марат Хамитович, доктор биологических наук, профессор,

старший научный сотрудник лаборатории экспериментальной экологии

Шагидуллин Рифгат Роальдович, доктор химических наук,

член-корреспондент Академии наук Республики Татарстан, директор

Институт проблем экологии и недропользования Академии наук Республики Татарстан (2. Казань, Российская Федераџия)

Аннотащия. В экспериментах с нематодами линии дикого типа N2 и мутантных линий LX636 (dop1(vs101)) и LX703 (dop-3(vs106)) с нуль-мутациями генов рецепторов дофамина DOP-1 и DOP-3 исследовалось влияние дофамина на устойчивость плавания, индуцированного механическим стимулом, к действию 
температуры $36^{\circ} \mathrm{C}$. Показано, что в концентрациях 0,5-1,0 мМ дофамин повышает теплоустойчивость поведения C. elegans линии дикого типа N2, а в концентрациях 7,5-15,0 мМ, напротив, вызывает ее снижение. Нуль-мутация гена рецептора дофамина dop-3 предотвращает снижение теплоустойчивости C. elegans дофамином, а нуль-мутация гена рецептора дофамин $d o p-1$, напротив, вызывает достоверное повышение чувствительности теплоустойчивости поведения к дофамину. В связи с известными представлениями о том, что причиной теплового нарушения поведения C. elegans является дефицит ацетилхолина, вызванный ингибированием его секреции гипертермией, влияние дофамина на теплоустойчивость поведения может быть объяснено действием дофамина на секрецию ацетилхолина моторными нейронами. Известно, что в моторных нейронах C. elegans происходит коэкспрессия генов рецепторов DOP-1 и DOP-3, а активация этих рецепторов, в свою очередь, вызывает противоположно направленные изменения секреции дофамина.

Ключевые слова: почвенная нематода Caenorhabditis elegans; теплоустойчивость плавания, индуцированного механическим стимулом; дофамин; гены рецепторов дофамина DOP-1 и DOP-3; нуль-мутации генов рецепторов дофамина $d o p-1$ и $d o p-3$; дефицит ацетилхолина в организме; регуляция теплоустойчивости организма дофамином.

\section{Введение}

Дофамин принимает участие в осуществлении основных интегративных функций центральной нервной системы человека и млекопитающих [1-3]. Нервная система является мишенью действия негативного влияния высокой температуры на организмы человека и животных как позвоночных, так и беспозвоночных [4-9]. Причиной высокой чувствительности нервной системы к высокой температуре являются нарушения синаптических связей между нейронами и нейронами и мышцами, обусловленные сильным влиянием температуры на процессы синтеза и секреции нейромедиаторов в нейронах и мышцах. В настоящее время во многом остается открытым вопрос о том, какие типы синапсов нарушаются высокой температурой. Дофамин является одним из основных модуляторов синаптических связей в нервной системе $[1 ; 3 ; 10]$. Поэтому возможно его участие как в нарушениях синаптической передачи высокой температурой, так и в компенсации этих нарушений. Молекулярные и клеточный механизмы функций нервной системы высококонсервативны в эволюции. Поэтому из-за исключительной сложности организации нервных систем человека и грызунов для изучения процессов, происходящих в нервной системе в норме и при патологии, последние десятилетия в качестве удобной модели широко используется простая нервная система свободноживущей почвенной нематоды Caenorhabditis elegans Maupas. Ранее нами было показано, что нервная система стала мишенью негативного влияния высокой температуры на многоклеточный организм животных уже на ранней стадии эволюции у таких простых организмов животных, как почвенная нематода C. elegans [7-9]. Показано, что одной из основных причин теплового нарушения поведения C.elegans является дефицит в организме ацетилхолина (АХ), наступающий в результате теплового ингибирования его секреции нейронами [8-9]. В то же время известно, что секреция $\mathrm{AX}$ моторными нейронами C. elegans модулируется биогенными аминами, такими как дофамин и серотонин [11-12]. Это позволяет предположить, что дофамин может принимать участие в регуляции теплоустойчивости организма C. elegans. Целью работы явилась проверка этой гипотезы в экспериментах с нематодами линии дикого типа N2 и мутантных линий LX636 (dop-1(vs101)) и LX703 (dop-3(vs106)) с нуль-мутациями генов рецепторов дофамина DOP-1 и DOP-3 соответственно.

\section{Материалы и методы исследования}

C. elegans выращивали при $22^{\circ} \mathrm{C}$ в чашках Петри со стандартной средой выращивания нематод (3 г/л $\mathrm{NaCl}, 17$ г/л бактоагар, 2,5 г/л бактопептон, 5 мг/л холестерин, $1 \mathrm{MM} \mathrm{CaCl}, 1 \mathrm{MM} \mathrm{MgSO}_{4}, 25$ мл/л калийфосфатный буфер (pH 6,0)) засеянных E.coli OP50 [13]. В работе использованы линии C. elegans дикого типа N2 Bristol и мутантные линии LX636 (dop-1(vs101)) и LX703 (dop-3(vs106)) с нуль-мутациями генов рецепторов дофамина DOP-1 и DOP-3 соответственно. Все линии C. elegans получены из Caenorhabditis Genetic center. Эксперименты по измерению теплоустойчивости поведения проводили в NG буфере (3 г/л $\mathrm{NaCl}, 1 \mathrm{мM} \mathrm{CaCl} 2,1 \mathrm{мM} \mathrm{MgSO}$, и 25 мл/л калийфосфатный буфер $(\mathrm{pH} \mathrm{6,0))} \mathrm{[13].} \mathrm{Для}$ каждого эксперимента червей отмывали от среды выращивания, бактерий и метаболитов и рассаживали по одной особи в стеклянные стаканчики с 1 мл NG буфера. Дофамин вводили в среду одновременно с нематодами. Нематод инкубировали 30 мин. при $22^{\circ} \mathrm{C}$ в стаканчиках с дофамином и без него (контрольные варианты). Сразу после этого стаканчики с червями помещали в ультратермостат TW-2.02 с температурой $36^{\circ} \mathrm{C}$. Нарушения поведения нематод регистрировали с использованием стереоскопического микроскопа SMZ-05. Критериями устойчивости поведения при постоянной температуре $36^{\circ}$ были среднее время нарушения координации поведения (плавание, индуцированное механическим стимулом (встряхивание пробирки с червем)) и среднее время потери червями способности к плаванию, индуцированному механическим стимулом. Нарушения координации поведения проявлялись в нарушениях координации локомоторных мышц, необходимой для синусоидальных движений тела при плавании и в неспособности поддерживать плавание в течение 10 сек. после механического стимула. Для нейрофармакологического анализа поведения использовали дофамин фирмы Sigma.

Необходимо отметить, что концентрации веществ, используемые нами для нейрофармакологического анализа термотолерантности C. elegans, как правило, очень высокие $\left(10^{-3} \mathrm{M}\right.$ и более) [7-9]. Столь высокие концентрации обусловлены хорошо известной особенностью C. elegans как модельного организма. Организм C. elegans обладает очень низкой чувствительностью к большинству веществ в окружающей среде из-за наличия кутикулы с крайне низкой проницаемостью для многих органических и неорганических веществ. Поэтому концентрации лекарственных веществ и токсикантов, эффективные для изменения поведения C. elegans, очень высоки [14-16]. 
Эксперименты проводили с февраля по апрель. В каждом варианте эксперимента, проведенном в трех повторностях, использовано 30 червей. Статистическую обработку результатов проводили с использованием углового преобразования Фишера $\varphi^{*}$.

\section{Результаты}

Для выяснения возможной роли дофамина в регуляции устойчивости организма C. elegans к гипертермии были проведены эксперименты, в которых исследовалось влияние дофамина на теплоустойчивость плавания, индуцированного механическим стимулом. При постоянном действии высокой температуры на C. elegans линии дикого типа N2 изнаО возможной роли рецепторов дофамина DOP-1 и DOP-3...

Таблица 1 - Влияние дофамина на теплоустойчивость поведения C. elegans линии дикого типа N2

\begin{tabular}{|l|c|c|c|c|c|}
\hline \multicolumn{1}{|c|}{ Условия эксперимента } & \multicolumn{5}{|c|}{ Дофамин, мМ } \\
\cline { 2 - 6 } & 0 & 0,5 & 1,0 & 7,5 & 15,0 \\
\hline $\begin{array}{l}\text { Среднее время появления ошибок } \\
\text { моторной программы плавания при } 36^{\circ} \mathrm{C} \text { (минуты) }\end{array}$ & $41 \pm 2$ & $66 \pm 2$ & $69 \pm 3$ & $28 \pm 1$ & $23 \pm 2$ \\
\hline Среднее время теплового паралича при $36^{\circ} \mathrm{C}$ (минуты) & $84 \pm 3$ & $86 \pm 4$ & $85 \pm 3$ & $60 \pm 2$ & $53 \pm 2$ \\
\hline
\end{tabular}

Известной особенностью организмов нематод является чрезвычайно низкая проницаемость их кутикулы для большинства химических соединений, из-за которой концентрации многих лекарств и токсикантов, эффективные для изменения поведения C.elegans, также чрезвычайно высоки $\left(10^{-3}-10^{-2} \mathrm{M}\right)[14$ 16]. Поэтому дофамин вызывает изменения локомоции и размножения C. elegans в концентрациях 120 мМ [12; 17-18]. Этот же диапазон концентраций дофамина был использован нами для изучения его действия на устойчивость плавания, индуцированного механическим стимулом, к экстремальной высокой температуре $36^{\circ} \mathrm{C}$.

Известно, что при оптимальной температуре среды экзогенный дофамин в концентрации 10-20 мМ вызывает снижение и прекращение спонтанной двигательной активности $C$. elegans [12]. В то же время при температуре $22^{\circ} \mathrm{C}$ при действии этих концентраций дофамина нематоды полностью сохраняют способность к плаванию, индуцированному механическим стимулом. При постоянной температуре $36^{\circ} \mathrm{C}$ дофамин, напротив, изменяет поведение C. elegans линии дикого типа N2 со сложной зависимостью до- чально происходят нарушения координации мышц тела, необходимой для синусоидальных движений тела при плавании без потери способности к плаванию в течение 10 сек. после механического стимула. Увеличение времени экспозиции к температуре $36^{\circ} \mathrm{C}$ приводит к полной потере способности к плаванию, индуцированному механическим стимулом (табл. 1). Поэтому среднее время проявления ошибок моторной программы плавания и среднее время теплового паралича нематод являются показателями устойчивости поведения C. elegans к экстремальному тепловому стрессу [7-9].

Таблица 2 - Теплоустойчивость поведения нематод линий N2, LX636 (dop-1(vs101)) и LX703 (dop-3(vs106)

\begin{tabular}{|c|c|c|c|c|}
\hline & & Линия N2 & $\begin{array}{l}\text { Линия LX636 } \\
(\text { dop-1(vs101)) }\end{array}$ & $\begin{array}{l}\text { Линия LX703 } \\
(\text { dop-3(vs106) })\end{array}$ \\
\hline \multirow{2}{*}{$\begin{array}{l}\text { Экспе- } \\
\text { римент } \\
\text { № } 1 \\
\end{array}$} & $\begin{array}{l}\text { Среднее время появления ошибок моторной программы } \\
\text { плавания при } 36^{\circ} \mathrm{C} \text { (минуты) }\end{array}$ & $38 \pm 2$ & $69 \pm 3$ & $37 \pm 3$ \\
\hline & Среднее время теплового паралича при $36^{\circ} \mathrm{C}$ (минуты) & $77 \pm 3$ & $92 \pm 4$ & $81 \pm 3$ \\
\hline \multirow{2}{*}{$\begin{array}{l}\text { Экспе- } \\
\text { римент } \\
\text { № } 2\end{array}$} & $\begin{array}{l}\text { Среднее время появления ошибок моторной программы } \\
\text { плавания при } 36^{\circ} \mathrm{C} \text { (минуты) }\end{array}$ & $42 \pm 2$ & $71 \pm 2$ & $44 \pm 3$ \\
\hline & Среднее время теплового паралича при $36^{\circ} \mathrm{C}$ (минуты) & $78 \pm 3$ & $96 \pm 3$ & $79 \pm 2$ \\
\hline \multirow{2}{*}{$\begin{array}{l}\text { Экспе- } \\
\text { римент } \\
\text { № } 3\end{array}$} & $\begin{array}{l}\text { Среднее время появления ошибок моторной программы } \\
\text { плавания при } 36^{\circ} \mathrm{C} \text { (минуты) }\end{array}$ & $44 \pm 2$ & $72 \pm 3$ & $42 \pm 2$ \\
\hline & Среднее время теплового паралича при $36^{\circ} \mathrm{C}$ (минуты) & $83 \pm 3$ & $101 \pm 4$ & $86 \pm 3$ \\
\hline
\end{tabular}

В табл. 2 приведены результаты трех независимых экспериментов, в которых сравнивалась теплоустойчивость поведения нематод линии дикого типа N2 и двух мутантных линий. Эти результаты показывают, что нуль-мутация гена рецептора дофамина DOP-3 не вызывает достоверные изменения устойчивости поведения C. elegans к действию экстремальной высокой температуры. В то же время следствием нуль-мутации гена рецептора DOP-1 является за-эффект (табл. 1). Относительно низкие концентрации дофамина $(0,5-1,0 \mathrm{MM})$ достоверно повышают теплоустойчивость моторной программы плавания, индуцированного механическим стимулом, хотя устойчивость нематод к тепловому параличу при этом не изменяется (табл. 1). В то же время в концентрациях 7,5-15,0 мМ дофамин вызывает противоположно направленные изменения теплоустойчивости поведения, проявляющиеся в снижении среднего времени как проявления ошибок моторной программы плавания, так и теплового паралича нематод (табл. 1).

Для проверки предположения о возможности регуляции теплоустойчивости организма C. elegans активацией рецепторов дофамина DOP-1 и DOP-3 были проведены эксперименты с нематодами линии дикого типа N2 и мутантных линий LX636 (dop1(vs101)) и LX703 (dop-3(vs 106)) с нуль-мутациями генов рецепторов дофамина DOP-1 и DOP-3 соответственно. В этих экспериментах сравнивалась устойчивость поведения к действию экстремальной высокой температуры $36^{\circ} \mathrm{C}$ у нематод линии N2 и мутантных линий в контрольных экспериментах и при введении в среду экзогенного дофамина значительное повышение теплоустойчивости поведения C. elegans, проявляющееся как в увеличении среднего времени появления ошибок моторной программы плавания, индуцированного механическим стимулом, так и теплового паралича нематод при действии температуры $36^{\circ} \mathrm{C}$.

Результаты экспериментов, представленных в табл. 3, показывают, что нуль-мутация гена рецептоpa DOP-3 вызывает сильное снижение чувствитель- 
ности C. elegans к действию относительно высоких концентраций дофамина (7,5-15,0 мМ). Напротив, нуль-мутация гена рецептора DOP-1 увеличивает чувствительность поведения C. elegans к действию дофамина, который ускоряет наступление теплового паралича в концентрациях 3-7 мМ (табл. 3).

Таблица 3 - Чувствительность теплоустойчивости поведения к дофамину у нематод линий N2, LX636 (dop-1(vs101)) и LX703 (dop-3(vs106))

\begin{tabular}{|l|c|c|c|c|}
\hline \multirow{2}{*}{} & \multicolumn{4}{|c|}{$\begin{array}{c}\text { Среднее время теплового паралича } \\
\text { при } 36^{\circ} \mathrm{C} \text { (минуты) }\end{array}$} \\
\cline { 2 - 5 } & \multicolumn{4}{|c|}{ Дофамин, мМ } \\
\cline { 2 - 5 } & 0 & 3 & 7,5 & 15 \\
\hline Линия N2 & $81 \pm 3$ & $75 \pm 2$ & $58 \pm 3$ & $51 \pm 2$ \\
\hline $\begin{array}{l}\text { Линия LX636 } \\
(\text { dор-1(vs101) })\end{array}$ & $97 \pm 3$ & $63 \pm 3$ & $49 \pm 4$ & $43 \pm 2$ \\
\hline $\begin{array}{l}\text { Линия LX703 } \\
(\text { dop-3(vs106) })\end{array}$ & $83 \pm 2$ & $85 \pm 3$ & $81 \pm 4$ & $87 \pm 3$ \\
\hline
\end{tabular}

\section{Обсуждение результатов}

У C. elegans дофамин принимает участие в регуляции локомоции и размножения [17-18]. Ранее нами было показано, что нейротоксин 6-гидроксидофамин (6-OHDA) снижает устойчивость организма C. elegans к экстремальной высокой температуре [7]. Этот нейротоксин вызывает селективную нейродегенерацию дофаминергических нейронов у позвоночных и у беспозвоночных, таких как C. elegans [19]. У C. elegans, обработанных 6-OHDA, дофамин повышает теплоустойчивость поведения в концентрациях 300-600 мкМ [7].

В этой работе показано, что в концентрациях $0,5-$ 1,0 мМ дофамин повышает теплоустойчивость поведения и в экспериментах с интактными нематодами (табл. 1). В то же время зависимость эффекта дофамина от его концентрации имеет куполообразный характер, и при концентрациях дофамина 7,515,0 мМ происходит не повышение, а снижение теплоустойчивости C. elegans (табл. 1). В связи с тем, что высокие концентрации экзогенного дофамина, эффективные в экспериментах с C. elegans, объясняются низкой проницаемостью кутикулы нематод для дофамина, их действие на локомоцию и откладку яиц рассматривается как следствие повышения концентрации дофамина в организме в физиологическом диапазоне изменения его концентраций [12; 17-18]. Поэтому результаты наших экспериментов свидетельствуют о возможности регуляции теплоустойчивости C. elegans дофамином в двух направлениях.

Известно, что действие дофамина на поведение и физиологическое состояние организма C.elegans осуществляется активацией нескольких типов рецепторов, включающих в себя рецепторы дофамина DOP-1 и DOP-3 [12; 20-21]. Эти рецепторы являются трансмембранными белками, сопряженными с несколькими типами G-белков, запускающими несколько типов каскадов внутриклеточных посредников. Рецептор DOP-3 сопряжен с $\mathrm{G} \alpha_{0}$, а рецептор DOP-1 сопряжен с $\mathrm{G} \alpha_{\mathrm{q}}[12 ; 20-21]$. Известно, что активация этих двух рецепторов дофамина вызывает антагонистические эффекты на клеточном уровне, проявляющиеся на уровне организма [12]. Этим могут объясняться качественные различия изменений чувствительности теплоустойчивости поведения C. elegans к дофамину, вызванных нуль-мутациями генов DOP-1 и DOP-3 (табл. 3).

Ранее нами было показано, что одной из причин нарушения поведения C. elegans экстремальной высокой температурой является дефицит ацетилхолина (AX) в организме, проявляющийся в результате ингибирования секреции АХ нейронами [8-9]. Коэкспрессия генов dop-1 и dop-3 происходит во многих нейронах C.elegans, включая холинергические моторные нейроны [12; 20-21]. Известно, что у C. elegans снижение спонтанной двигательной активности наличием пищи (E. coli) и прекращение этой активности экзогенным дофамином происходит в результате снижения скорости секреции АХ моторными нейронами [12]. Информация о наличии E. coli в cpeде воспринимается сенсорными нейронами и вызывает секрецию дофамина, который снижает скорость секреции AX активацией DOP-3 рецепторов в моторных нейронах [12]. Экзогенный дофамин снижает спонтанную двигательную активность C. elegans также активацией DOP-3 в моторных нейронах [12]. Поэтому активация DOP-3 экзогенным дофамином должна усиливать дефицит AX, вызванный высокой температурой, и, как следствие, снижать теплоустойчивость поведения C. elegans. Подтверждением этого предположения является резистентность нематод линии с нуль-мутацией гена $d o p-3$ к действию дофамина на теплоустойчивость C. elegans (табл. 3).

В связи с тем, что действие экзогенного дофамина на нервную систему C. elegans имитирует состояние организма с повышенным уровнем эндогенного дофамина [12; 17-18], результаты этой работы показывают возможность регуляции теплоустойчивости поведения C. elegans активацией DOP-3 рецепторов в моторных холинергических нейронах, вызывающей снижение скорости секреции ими АХ.

Повышение чувствительности теплоустойчивости C. elegans к дофамину, вызванное нуль-мутацией гена рецептора DOP-1 (табл. 3), объясняется противоположно направленными изменениями активности моторных нейронов при связывании дофамина с DOP-3 и DOP-1 рецепторами в этих нейронах [12]. B то же время остается открытым вопрос о том, почему теплоустойчивость поведения C. elegans в среде без дофамина значительно выше у нематод с нульмутацией гена dop-1, чем у нематод линии дикого типа N2 (табл. 2). Это повышение не может быть следствием активации рецепторов DOP-1 в моторных нейронах, так как активация дофамином рецепторов DOP-1 и DOP-3 вызывает противоположно направленные изменения секреции АХ этими нейронами [12]. Прекращении активации эндогенным дофамином рецептора DOP-1 вследствие нуль-мутации гена $d o p-1$ должно приводить к снижению, а не повышению теплоустойчивости поведения C. elegans. В то же время известно, что у C. elegans экспрессия гена dop-1 происходит не только в моторных, но и во многих других нейронах $[12 ; 20]$.

Нервная система является самой чувствительной мишенью действия экстремальной высокой температуры на организм C. elegans [7-9] и высших беспозвоночных [4-5; 22]. В свою очередь, холинергические моторные нейроны не могут быть единственной мишенью негативного влияния гипертермии на ор- 
ганизм C. elegans, так как частичное ингибирование ацетилхолинэстеразы (АХ-эстеразы) неостигмином ослабляет, но не предотвращает нарушения поведения, вызванные действием постоянной температуры $36^{\circ} \mathrm{C}[8]$. Поэтому активация дофамином DOP-1 peцепторов в нейронах, не являющихся моторными, может регулировать теплоустойчивость C.elegans, вызывая ее снижение. В этом случае следствием нуль-мутации гена dop-1 является повышение теплоустойчивости C. elegans (табл. 2). Ранее нами был показан сходный эффект нуль-мутации гена рецептора серотонина SER-4 [23]. Качественное различие между действием мутаций генов dop-1 и ser-4 на теплоустойчивость $C$. elegans заключается в том, что при сходном их влиянии на базовую теплоустойчивость, нуль-мутация ser-4 снижает ее чувствительность к экзогенному серотонину [23], а у нематод с нуль-мутацией гена $d o p-1$ чувствительность к дофамину сохраняется (табл. 3). В то же время известно, что регуляция функций нервной системы дофамином осуществляется не только сравнительно быстрыми (минуты) изменениями состояния нейронов, но и экспрессией генов, изменяющей поведение через несколько часов после введения дофамина в организм [24]. Эффекты экзогенного дофамина, обусловленные экспрессией генов в нейронах, не могли выявляться в условиях наших экспериментов из-за их скоротечности, и для выяснения их возможной роли в регуляции теплоустойчивости C. elegans необходимы дополнительные исследования.

\section{Выводы}

1. Дофамин изменяет теплоустойчивость поведения C. elegans в двух направлениях: повышение устойчивости к температуре $36^{\circ} \mathrm{C}$ в концентрациях 0,5-1,0 мМ и ее снижение в концентрациях 7,515,0 MM.

2. Нуль-мутация гена рецептора дофамина dop-3 блокирует снижение теплоустойчивости, индуцированное дофамином, в то время как нуль-мутация гена рецептора dop-1 достоверно сенситизирует теплоустойчивость к действию дофамина.

3. Качественные различия влияния нуль-мутаций генов рецепторов дофамина $d o p-1$ и dop-3 на чувствительность теплоустойчивости C. elegans к дофамину могут быть объяснены наличием коэкспрессии этих генов в моторных нейронах при противоположно направленном влиянии активации рецепторов DOP-1 и DOP-3 на секрецию AX [12].

\section{Список литературы:}

1. Knable M.B., Weinberger D.R. Dopamine, the prefrontal cortex and schizophrenia // J. Psycopharmacol. 1997. Vol. 11. P. 123-131.

2. Koob G.F., Sanna P.P., Bloom F.E. Neuroscience of addiction // Neuron. 1998. Vol. 21. P. 467-476.

3. Lang F.E., Lozano A.M. Parkinson's disease. First of two parts // New Engl. J. Med. 1998. Vol. 339. P. 1044-1053.

4. Robertson R.M. Modulation of neural circuit operation by prior environmental stress // Integr. Comp. Biol. 2004. Vol. 44. P. 21-27.

5. Robertson R.M. Thermal stress and neural function: adaptive mechanisms in insect model systems // Journal of Thermal Biology. 2004. Vol. 29. P. 351-358.

6. Bouchama A., Knochel J.P. Heat stroke // New Engl. J. Med. 2002. Vol. 346. P. 1978-1988.
О возможной роли рецепторов дофамина DOP-1 и DOP-3..

7. Kalinnikova T.B., Kolsanova R.R., Gainutdinov M.Kh. Caenorhabditis elegans as a convenient model organism for understanding heat stress effects upon intact nervous system // Heat Stress: Causes, Treatment and Prevention / Eds. S. Josipovich and E. Ludwig. NY: Nova Science Publishers, 2012. P. 113-140.

8. Kalinnikova T.B., Shagidullin R.R., Kolsanova R.R., Osipova E.B., Zakharov S.V., Gainutdinov M.Kh. Acetylcholine deficiency in Caenorhabditis elegans induced by hyperthermia can be compensated by ACh-esterase inhibition or activation of GAR-3 mAChRs // Environ. Nat. Resour. Res. 2013. Vol. 3. P. 98-113.

9. Kalinnikova T.B., Kolsanova R.R., Belova E.B., Shagidullin R.R., Gainutdinov M.Kh. Opposite responses of the cholinergic nervous system to moderate heat stress and hyperthermia in two soil nematodes // J. Therm. Biol. 2016. Vol. 62. P. 37-49.

10. Vidal-Gadea A., Topper S., Young L., Crisp A., Kressin L., Elbel E., Maples T., Brauner M., Erbguth K., Axelrod A., Gottschalk A., Siegel D., Pierce-Shimomura T. Caenorhabditis elegans selects distinct crawling and swimming gaits via dopamine and serotonin // PNAS. 2011. Vol. 108. P. 17504-17509.

11. Nurrish S., Ségalat L., Kaplan J.M. Serotonin inhibition of synaptic transmission: $\mathrm{G} \alpha_{0}$ decreases the abundance of UNC-13 at release site // Neuron. 1999. Vol. 24. P. 231-242.

12. Chase D.L., Pepper J.S., Koelle M.R. Mechanism of extrasynaptic dopamine signaling in Caenorhabditis elegans // Nature Neurosci. 2004. Vol. 7. P. 1096-1103.

13. Brenner S. The genetics of Caenorhabditis elegans // Genetics. 1974. Vol. 77. P. 71-94.

14. Anderson G.L., Cole R.D., Williams P.L. Assessing behavioral toxicity with Caenorhabditis elegans // Environ. Toxicol. Chem. 2004. Vol. 23. P. 1235-1240.

15. Dittmann J.S., Kaplan J.M. Behavioral impact of neurotransmitter-activated GPCRs: muscarinic and $\mathrm{GABA}_{\mathrm{b}}$ receptors regulate C. elegans locomotion // J. Neurosci. 2008. Vol. 28. P. 7104-7112.

16. Glosh R., Mohammadi A., Kruglyak L., Ryu W.S. Multiparameter behavioral profiling reveals distinct thermal response regimes in Caenorhabditis elegans // BMC Biol. 2012. Vol. 10. P. 1-17.

17. Sawin E.R., Ranganathan R., Horvitz H.R. C. elegans locomotory rate is modulated by the environment through a dopaminergic pathway and by experience through a serotonergic pathway // Neuron. 2000. Vol. 26. P. 619-631.

18. Schafer W.R., Kenyon S. A calcium-channel homologue required for adaptation to dopamine and serotonin in Caenorhabditis elegans // Nature. 1995. Vol. 375. P. 73-78.

19. Nass R., Blakely R.D. The Caenorhabditis elegans dopaminergic system: opportunities for insight into dopamine transport and neurodegeneration // Ann. Rev. Pharmacol. Toxicol. 2003. Vol. 43. P. 521-544.

20. Sanyal S., Wintle R.F., Kindt K.S., Nuttley W.M., Arvan R., Fitzmaurice P., Bigras E., Merz D.C., Hébert T.E., van der Kooy D., Schafer W.R., Culotti J.G., van Tol H.H.M. Dopamine modulates the plasticity of mechanosensory responses in Caenorhabditis elegans // EMBO J. 2004. Vol. 23. P. 473-482.

21. Ezak M.J., Ferkey D.M. The C. elegans D2-like dopamine receptor DOP-3 decreases behavioral sensitiv- 
ity to the olfactory stimulus 1-octanol // PLoS One. 2010. Vol. 5. DOI: 10.1371/journal.pone.0009487.

22. Hoffmann A.A., Sørensen J.G., Loeschke V. Adaptation of Drosophila to temperature extremes: bringing together quantitative and molecular approaches // J. Therm. Biol. 2003. Vol. 28. P. 175-216.

23. Kalinnikova T.B., Kolsanova R.R., Shagidullin R.R., Osipova E.B., Gaynutdinov M.Kh. On the role of gene of SER-4 serotonin receptor in thermotolerance of Caenorhabditis elegans behavior // Russian J. Genetics. 2013. Vol. 49. P. 363-366.

24. Suo S., Ishiura S. Dopamine modulates acetylcholine release via octopamine and CREB signaling in Caenorhabditis elegans // PLoS ONE. 2013. Vol. 8. DOI: 10.1371/journal.pone.0072578.

\section{THE POSSIBLE ROLE OF DOPAMINE RECEPTORS DOP-1 AND DOP-3 IN BEHAVIOR THERMOTOLERANCE REGULATION OF CAENORHABDITIS ELEGANS MAUPAS} (C) 2018

Kalinnikova Tatiana Borisovna, candidate of biological sciences, head of the Laboratory of Experimental Ecology Kolsanova Rufina Rifkatovna, candidate of biological sciences, researcher of the Laboratory of Experimental Ecology

Belova Evgenia Borisovna, junior researcher of the Laboratory of Experimental Ecology Research Institute for Problems of Ecology and Mineral Wealth Use of Tatarstan Academy of Sciences (Kazan, Russian Federation)

Khakimova Dilyara Makhmutrievna, candidate of medical sciences, senior lecturer of the Department of Morphology and General Pathology Kazan (Volga Region) Federal University (Kazan, Russian Federation)

Gainutdinov Marat Khamitovich, doctor of biological sciences, professor, senior researcher of the Laboratory of Experimental Ecology

Shagidullin Rifgat Roaldovich, doctor of chemical sciences, corresponding member of the Tatarstan Academy of Sciences, director Research Institute for Problems of Ecology and Mineral Wealth Use of Tatarstan Academy of Sciences (Kazan, Russian Federation)

Abstract. The paper investigates dopamine influence on the tolerance of swimming, induced by mechanical stimulus, to the temperature of $36^{\circ} \mathrm{C}$ during the experiments with nematodes of wild type strain $\mathrm{N} 2$ and mutant strains LX636 (dop-1(vs101)) and LX703 (dop-3(vs106)) with null-mutations of genes of dopamine receptors DOP-1 and DOP-3. The authors have shown that dopamine in concentrations $0,5-1,0 \mathrm{mM}$ increased the behavior thermotolerance of $C$. elegans while in concentrations 7,5-15,0 dopamine caused its decrease. Null-mutation of dopamine receptor gene $d o p-3$ prevented the decrease of $C$. elegans thermotolerance by dopamine. On the contrary, null-mutation of dopamine receptor gene dop- 1 caused significant rise in sensitivity of behavior thermotolerance to dopamine. In connection with well-known conceptions assuming that the reason of heat damage of $C$. elegans behavior is acetylcholine deficiency due to inhibition of its secretion by hyperthermia, the dopamine influence on behavior thermotolerance can be accounted for the dopamine influence on acetylcholine secretion by motor neurons. It is known that in C. elegans motor neurons the coexpression of genes of receptors DOP-1 and DOP-3 takes place. Activation of these receptors in turn causes opposite changes in dopamine secretion.

Keywords: soil nematode Caenorhabditis elegans; swimming thermotolerance induced by mechanical stimulus; dopamine; genes of dopamine receptors DOP-1 and DOP-3; null-mutations of dopamine receptors genes dop-1 and dop-3; acetylcholine deficiency in organism; regulation of organism thermotolerance by dopamine.

\section{ОЦЕНКА ЭКОЛОГИЧЕСКОГО СТАТУСА МИКРОБНОЙ ПОПУЛЯЦИИ ИЗ ОСНОВНОГО САПРОТРОФНОГО МИКРОБНОГО ПУЛА ДЕРНОВО-ПОДЗОЛИСТОЙ ПОЧВЫ ПРИ БИОХИМИЧЕСКОЙ ДЕСТРУКЦИИ ДИАТОМИТА ИНЗЕНСКОГО МЕСТОРОЖДЕНИЯ В УСЛОВИЯХ ЛАБОРАТОРНОГО ЭКСПЕРИМЕНТА}

Козлов Андрей Владимирович, кандидат биологических наук, доцент кафедры экологического образования и рационального природопользования Нижегородский государственный педагогический университет имени Козьмы Минина (2. Нижний Новгород, Российская Федерация)

Куликова Алевтина Христофоровна, доктор сельскохозяйственных наук, заведующий кафедрой почвоведения, агрохимии и агроэкологии

Ульяновский государственный аграрный университет имени П.А. Столыпина (2. Ульяновск, Российская Федеращия)

Уромова Ирина Павловна, доктор сельскохозяйственных наук, профессор кафедры биологии, химии и биолого-химического образования Нижегородский государственный педагогический университет имени Козьмы Минина (2. Нижний Новгород, Российская Федерация)

Аннотациия. В настоящей статье рассматривается реакция сапротрофной и аммонифицирующей микробных популяций, выделенных из дерново-подзолистой легкосуглинистой почвы Нижегородской области, на 